inoculated with disks of agar free from the fungus remained healthy throughout the whole experimental period.

The experiments showed that young seedlings of the two cotton varieties are very susceptible to attack by Rhizoctonia solani, and susceptibility decreases significantly with increased age of seedlings until they are completely resistant after about 19 days from emergenee when raised at $19^{\circ}-34^{\circ} \mathrm{C}$., 12-15 days at $15^{\circ}-28^{\circ} \mathrm{C}$, and $19-22$ days when raised at $9^{\circ}-18^{\circ} \mathrm{C}$. The decreased susceptibility with increased age is in full agreement with the previous findings of other investigators; but the fact that cotton seedlings became completely resistant to Rhizoctonia attack after a certain period of time, governed by the range of temperature prevailing during germination and emergence, is contradictory to the results of Matus ${ }^{2}$, who claims that cotton plants are invaded by Corticium vagum throughout the growing period.

Seedlings of Giza 30 variety tend to remain susceptible to the fungus for somewhat longer periods than those of the Ashmouny variety, especially when raised at the lower temperature.

$$
\text { M. K. Tolba }
$$

A. H. Moubasher

Botany Department,

Faculty of Science,

University of Cairo. May 5.

Tint, Phytopath., 35, 440 (1945).

2 Matus, T., Ann. Phytopath. Soc. Japan, 13, 3 (1949).

${ }^{3}$ Linnasalmi, A., Ann. Bot. Soc. Vanamo, 26, 1 (1952).

- Koba, S., Ann. Phytopath. Sac. Japan, 18, 1 (1953).

\section{A Chromosome Number New to Linum}

THE genus Linum comprises some ninety species of which, apart from the garden cultivated plants (L. grandiflorum), $L$, usitatissimum is of economic importance. Chromosome numbers have been reported in the literature ${ }^{1-3}$ for thirty of these species, the range of somatic chromosome numbers being $16,18,20,28,30,32,36$, about 57 and about 86 .

L. mysorense Heyne is a wild species distributed in the mountainous regions of India and Ceylon at altitudes between 3,000 and $6,000 \mathrm{ft}$. Material of this species collected from the Western Himalayas and the Western Ghats in India was found by us to possess $2 n=60$ chromosomes, a number hitherto not reported for any naturally occurring species of Linum. During microsporogenesis, 30 bivalents were invariably noticed. The pollen was fully fertile and seed. setting abundant.

The high chromosome number and the regular bivalent formation observed during meiosis would suggest that $L$. mysorense is a polyploid functioning like a diploid. In view of this, the diminutive form exhibited by the species has perhaps an adaptive significance. The plants are dwarf, being $8-40 \mathrm{~cm}$. tall, and bear small yellow flowers, about $6 \mathrm{~mm}$. in diameter. The pollen grains measure $60 \cdot 16 \pm 0 \cdot 56 \mu$ in diameter and are significantly smaller than those of $L$. usitatissimum $(67 \cdot 50 \pm 0 \cdot 40 \mu)$, having $2 n=30$ chromosomes. The seeds also are very small $-0.8 \mathrm{~mm}$. long and $0.5 \mathrm{~mm}$. broad, the range of corresponding measurements in respect of $L$. usitatissimum being $2 \cdot 0-4 \cdot 0 \mathrm{~mm}$. and $1 \cdot 2-1.8 \mathrm{~mm}$. In peels of the lower and the upper epidermis of fully developed leaves, the stomatal length in the case of $L$. mysorense $(33 \cdot 3 \mu)$ was significantly greater than that in $L$. usitatissimum $(26 \cdot 6 \mu)$; the width of the stomata was about the same $(16 \cdot 6 \mu)$ in the two species.

We are grateful to Mr. V. C. Lele, of Simla, and Mr. V. D. Vartak, of Poona, for the seeds of $L$. mysorense.

\section{A. B. Joshi}

M. W. Hardas

Division of Botany,

Indian Agricultural Research Institute, New Delhi. April 26.

${ }^{1}$ Darlington, C. D., and Janaki Ammal, E. K. "Chromosome Atlas of Cultivated Plants" (Allen and Unwin, London, 1945).

${ }^{2}$ Rajan, S. S., Ind. J. Genet. Plant Breed., 12, 93 (1952).

${ }^{3}$ Tischler, G., "Die Chromosomenzahlen der Gefasspflanzen Mitteleuropas"' (Junk, 'S-Gravenhage, 1950).

\section{Chemical and Biological Determination . of Copper in Soil}

SwVERAL methods, chemical as well as biological, have been suggested for the determination of copper available to plants in soil. Steenbjerg's ${ }^{1}$ method has been used here since 1940, and consists in the extraction of copper from soil with dilute hydrochloric acid of such concentration as to result in $p \mathrm{H} 2 \cdot 00$ of the soil suspension after shaking for one hour. This method has in this laboratory during the past three years been compared with bioassays of copper by means of Aspergillus niger according to Mulder ${ }^{2}$. Both methods are somewhat laborious and do not yield readily reproducible results, inter alia, because the time of sampling and the length of sample storage influence the results of at least the chemical method.

Investigations have been conducted in order to devise a simpler and more reliable method,- and disodium-ethylenediaminetetra-acetate has been tried as an extracting agent, as suggested by Cheng and Bray ${ }^{3}$. The theoretical background for the extraction of heavy metals from soil by means of ethylenediaminetetra-acetic acid was recently discussed by Viro".

Preliminary tests were made in order to define the conditions of extraction, etc., and a two-hour extraction with a $0 \cdot 02-M$ ethylenediaminetetra. acetate solution at its natural $p \mathbf{H}(\mathbf{4} \cdot 5)$ was adopted; this results in a state of approximate equilibrium, at least in the case of soils containing less than 2 p.p.m. copper according to the method in question. Copper in the soil extract was determined colorimetrically as the diethyldithiocarbamate complex in the presence of an ammonium citrate solution of $p H \mathbf{H} \cdot 0$, which eliminates the interference due to other metals and prevents precipitation of iron.

The analytical procedure is as follows : $10 \mathrm{gm}$. of air-dry soil is shaken for one hour with $100 \mathrm{ml} .0 .02 \mathrm{M}$ ethylenediaminetetra-acetic acid solution. The suspension is filtered after standing for another hour, and an aliquot of the filtrate, with not more than $50 \mu \mathrm{gm}$. copper, is transferred to a $150-\mathrm{ml}$. separation funnel ; $50 \mathrm{ml}$. is usually convenient. Approximately $10 \mathrm{ml}$. of $1 M$ ammonium citrate solution is added, and after thorough shaking a further $1 \mathrm{ml} .1$ per cent solution of sodium diethyldithiocarbamate and $15 \mathrm{ml}$. carbon tetrachloride. After repeated thorough shaking for two minutes and standing until complete separa. tion of the aqueous and the carbon tetrachloride phase, the latter is run through a filter into a small measuring flask or directly into the photometric absorption cell. The colour intensity is measured on 